\author{
Federal Reserve Bank of New York \\ Staff Reports
}

\title{
Small Firms' Formalization: The Stick Treatment
}

\author{
Giacomo De Giorgi \\ Matthew Ploenzke \\ Aminur Rahman
}

Staff Report No. 728

May 2015

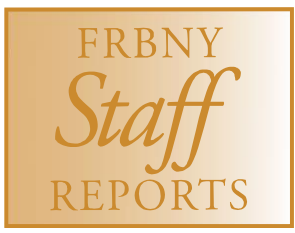

This paper presents preliminary findings and is being distributed to economists and other interested readers solely to stimulate discussion and elicit comments. The views expressed in this paper are those of the authors and do not necessarily reflect the position of the Federal Reserve Bank of New York or the Federal Reserve System. Any errors or omissions are the responsibility of the authors. 
Small Firms' Formalization: The Stick Treatment

Giacomo De Giorgi, Matthew Ploenzke, and Aminur Rahman

Federal Reserve Bank of New York Staff Reports, no. 728

May 2015

JEL classification: $\mathrm{O} 1$

\begin{abstract}
Firm informality is pervasive throughout the developing world, and Bangladesh is no exception. The informal status of many firms substantially reduces the tax basis and therefore affects the provision of public goods. The literature on encouraging formalization has focused predominantly on reducing the direct costs of formalization and has found negligible effects from such policies. In this paper, we focus on a stick intervention, which, to the best of our knowledge, is the first in a developing-country setting to deal with the most direct and dominant form of informality: the lack of registration with the tax authority and direct link to the country's potential revenue base and thus public goods provision. We implement an experiment in which firms are visited by representatives who deliver an official letter from the Bangladesh National Tax Authority stating that the firm is not registered and threatening punishment if it fails to register. We find that the intervention increases the rate of registration among treated firms, while firms located in the same market but not treated do not seem to respond significantly. We also find that only larger-revenue firms at the baseline respond to the threat and register. Our findings have at least two important policy implications: 1) the enforcement angle, which could be an important tool to encourage formalization; and 2) targeting of government resources for formalization to the high-end informal firms. The effects are generally small in level, leaving open the question of why many firms still do not register.
\end{abstract}

Key words: firms, informality, development

Corresponding author: De Giorgi, Federal Reserve Bank of New York (e-mail:

giacomo.degiorgi@ny.frb.org). Ploenzke: Federal Reserve Bank of New York. Rahman: World Bank Group. The authors are grateful to the PEDL (Private Enterprise Development for LowIncome Countries) initiative for partial funding under the SEED Grant \#168 and to seminar participants at the SME Initiative workshop at MIT. They thank officials from the Bangladesh National Board of Revenue, in particular Aminul Karim for partnering with them in this research project and Najmul Hossain and his team from Data International for implementing the field work. De Giorgi acknowledges financial support from the Spanish Ministry of Economy and Competitiveness, through the Severo Ochoa Programme for Centres of Excellence in R\&D (SEV2011-0075) and ECO2011-28822, and the EU through the Marie Curie CIG grant FP7-631510. The research was approved by the Stanford University Institutional Review Board. The views expressed in this paper are those of the authors and do not necessarily reflect the position of the Federal Reserve Bank of New York or the Federal Reserve System. 


\section{Introduction}

Firm informality, the most dominant form of which is lack of registration with tax authority, is pervasive throughout the developing world. According to available data, $60-80 \%$ of micro, small and medium businesses in developing countries are informal (IFC 2013). Bangladesh is no exception with about three quarters of firms not registered with the tax authority, resulting in a substantially reduced tax basis and therefore impacting the provision of public goods. At the same time formal and informal firms might coexist in a given market and sector and therefore compete with a substantially different costs structure.

Why do firms remain informal? A view, popularized by de Soto (1989) and which has substantially influenced developing country policies and donor-funded aid programs, is that these firms are willing to formalize but costly and cumbersome regulatory processes and bureaucratic red tapes are inhibiting them to formalize. This in turn has inspired simplification and streamlining of business entry and tax registration in recent years in a number of developing countries, including Bangladesh. For instance, according to the World Bank Doing Business database, 368 regulatory reforms took place in 149 economies between 2003 and 2012 resulting in a decline in the world average time to start a business from 50 days to 30, while the cost of starting a business is one-third of what it was prior to the reform (World Bank, 2013). Yet, we still see the majority of the firms in many of these countries remain in the informal sector.

A number of randomized controlled trials provided carrots in the form of lowering or eliminating the costs of registration and providing free information about the registration process but found no impact of such interventions on formalization (de Mel, McKenzie, and Woodruff (2012); De Giorgi and Rahman (2013)). Only paying cash-grants equivalent to one-half to one month of the median firm's profits leads to registration of around one-fifth of firms (de Mel, McKenzie, and Woodruff (2012)).

Firms may choose to remain informal simply because they do not perceive formalization as leading to better business outcomes and public goods provision. Also firms might perceive that the cost of remaining informal is relatively low, the expected value of penalties might simply be too low either because of the low probability of getting caught or the magnitude of the penalties. De Andrade, Bruhn, and McKenzie (2013) is one of the first studies that we are aware of that investigates the effect of stricter enforcement on formalization in a middle- 
income country. They find that while offering information on how to register and full waiver of the registration cost (approximately USD 200) has zero effect on firm registration, a visit from a municipal inspector to verify the proof of municipal licenses and a subsequent followup if they did not have one seems to increase the municipal registration by 21-27 percentage points. Further, there is no effect on a firm's registration by a neighboring firm being inspected. These findings suggest that sticks rather than carrots may be more effective at getting firms to formalize. While innovative, this stick intervention does not however deal with the most direct and dominant form of informality: the registration with tax authorities which includes a direct link to the country's potential revenue base and thus public goods provision.

In the current paper, we implement a "stick" intervention directly dealing with a country's tax authority. As far as we know, our intervention is the first in a low-income country that deals directly with the issue of enforcement and informality that has a direct link to the country's tax base as our focus is on registration with the national tax authority. As such, our paper has an important policy implication regarding the improvement of a state's enforcement capacity. A stylized fact about informality from cross-country analysis is that informality is negatively associated with a country's level of development (Loayza and Rigolini (2006); Schneider (2005)). This association is often said to arise because of burdensome regulatory regimes coupled with relatively low benefits of formalization in terms of public goods provision, access to credit, etc. in lower income countries. Another obvious, but largely overlooked, explanation is that of weak State's enforcement mechanisms and capacity. Our paper attempts to address this enforcement issue in an experimental setting in a low-income country.

In our experiment, firms are visited by tax representatives who deliver an official letter from the Bangladesh National Tax Authority on the threat of punishment if a firm fails to register with the tax authority within a given timeframe. We find that the intervention is effective at increasing the rate of registration among treated firms, and has no effect for firms located in the same market but not treated. This latter result is similar to the no-spillover effects found in De Andrade, Bruhn, and McKenzie (2013).

The effects are small in levels but extremely large in percent terms, relative to the control group. Up to three months from the intervention, only up to 17 percent of the firms declare to be registered in the treatment group versus 13 percent in the control group (post intervention), an even smaller share can give us their registration number or Tax Identification Number (TIN) 
(3.4 percent versus 1.1 percent) and even fewer firms are able to show us a valid tax ID card (3.1 percent versus 0.9 percent in the control group ex-post). We also find that only larger revenue firms at baseline respond to the threat and register. In fact we detect a large and statistically significant difference in the treatment effects for larger revenue firms of over 5 percentage points. Our findings have at least two important policy implications: i. the enforcement angle, which could be a crucial tool to encourage formalization; and ii. efficient targeting of government resources for formalization to the high-end informal firms.

Importantly however, we are left with a very large fraction of the firms yet unregistered even though threatened to be fined. Unfortunately, we cannot say whether this results from the threat lacking enough credibility or simply because small firms would not be profitable if they were to register. The fact that some firms registered must mean that they believed in the threat, and yet almost all of the treated firms confirm they were visited by an NBR representative. Further, the effects do not seem differential according to the number of firms which were treated in a given market, our presumption would be that if more firms are visited by the tax representative this should have made the potential threat more salient.

The rest of the paper proceeds as follows: in Section 2 we sketch a conceptual framework on the decision to register; Section 3 presents our intervention. Section 4 focuses on the research design. Section 5 describes the data. Section 6 presents our empirical analysis and Section 7 concludes.

\section{A Narrative on the Decision to Register}

A firm's decision to register rests upon the comparison of expected costs and benefits, both direct and indirect. In this paper our focus is on the effect of credible threats and penalties arising from remaining informal. Given the existing experimental evidence on the reduction of direct registration costs (De Andrade, Bruhn, and McKenzie (2013), De Giorgi and Rahman (2013)), we believe that the direct costs of registration are not a crucial determinant in the decision to formalize. We can thus summarize the decision rule to formalization in an expected 
present value framework as follows for any firm $f$ :

$$
\begin{aligned}
& \mathbf{V} \equiv \underbrace{E\left(\text { Revenues }^{1}-\text { Revenues }^{0}-\left(\text { Costs }^{1}-\text { Costs }^{0}\right)\right)}_{\Pi^{1}-\Pi^{0} \equiv \text { Expected Difference in Profits }} \\
& +\underbrace{p(D) P(D)}_{\text {Expected Penalties }}-(\underbrace{C}_{\text {Direct Costs }}+\underbrace{E\left(T\left(\Pi^{1}\right)\right)}_{\text {Indirect Costs }}) \geq 0 .
\end{aligned}
$$

Where the superscripts $s=0,1$ indicate the registration status. The Costs in $\Pi$ include all of the firm's costs excluding taxation and registration. Firm $f$ will register if and only if the discounted present value of profits in the registered state $\Pi^{1}$ minus profits in the unregistered state $\Pi^{0}$, taking into account the expected penalties $p(D) P(D)$, with $p($.$) and P($.$) being$ the probability of and the size of the punishment respectively, is larger than the costs, both direct $C$ (fees, and time) and indirect (future taxation) $T$ as well as the compliance with stricter regulations, e.g. labor regulations as well as safety standards and the like. We assume throughout that the treatment, i.e. $D=1$, made the expected penalties higher than in the no-intervention scenario, i.e. $p(D=1) P(D=1)>p(D=0) P(D=0)$. It is important to note here that we think of the indirect cost as $T\left(\Pi^{1}\right) \approx t_{0}+\tau_{\pi} \Pi^{1}$ where essentially there are some fixed costs $t_{0}$ arising once a firm is registered, e.g. compliance with accounting, labor regulations and so on, and standard proportional or progressive taxes $\left(\tau_{\pi} \Pi^{1}\right)$. Our current intervention, as we will detail later, randomly increased the expected punishment (or made more salient) arising from remaining informal. As our intervention only had personnel visiting the treatment firms, we model the intervention as an increase in $p$, the probability of being punished for lack of compliance. ${ }^{1}$ We therefore expect our treatment to push some firms over the threshold between remaining informal and registering. If $\operatorname{Cov}\left(\right.$ Revenues $^{1}$, Revenues $\left.^{0}\right)>0$ or alternatively $\operatorname{Cov}\left(\Pi^{1}, \Pi^{0}\right)>0$ and the tax system isn't strongly progressive $\frac{\partial t_{\pi}}{\partial \pi}<k$, with $k>0$ and small, we expect that more profitable firms will register as $p(D) P(D)$ increases for treatment firms. We can test two very stylized predictions in our data exploiting the randomized intervention:

\footnotetext{
${ }^{1}$ We should note that our intervention might have increased both $p$ as well as increased the perceived $P$ (the saliency of the fines). While we did not explicitly change the fines schedule, we might have made the size of the penalty more salient to the treatment firms. For some firms we might have actually lowered the perceived size of the fine, but we have no way of knowing this as we did not collect data on expectation or subjective size and probabilities.
} 


$$
\begin{array}{ll}
(H P-1): & \frac{\partial \operatorname{Prob}(\mathbf{V}>0)}{\partial p} \geq 0 \\
(H P-2): & \frac{\partial \operatorname{Prob}(\mathbf{V}>0)}{\partial p \partial \text { Revenues }^{0}} \geq 0 .
\end{array}
$$

That is to say that the treatment should have a non-negative effect on formalization (prediction $H P-1$ ), and that such an effect is concentrated amongst the larger revenues firms at baseline (prediction $H P-2) .^{2}$

\section{Intervention: The Stick}

The results of the studies cited above on providing information and reducing the actual or perceived direct costs of registration beg the question of whether a different approach would be successful in bringing firms out of informality. Our intervention focuses on the threat of punishment from the tax authority - Bangladesh National Board of Revenue (NBR) - based on the country's income tax law in case the treated informal firms do not register within a set time frame. We partnered with NBR in implementing this intervention. More specifically, in collaboration with NBR, we prepared a letter (see Appendix A.1 for an English version of the original letter) which clearly states that NBR notices that the owner of the concerned business currently does not posses a Tax Identification Number (TIN) and advises that the owner obtains the TIN number completely free of charge, either through an online registration process (the weblink for the registration is given in the letter) or by visiting the local tax office within 30 days of the receipt of the letter. The letter also emphasizes that after the deadline is over, the business may be inspected by the tax authority and failure to show the TIN certificate during that visit may result in significant monetary penalties and other legal consequences on the business as per the Income Tax Ordinance. The letter makes the business owners aware of all the vital business transactions (such as the renewal of a business license, obtaining various licenses and permits, e.g. construction permit, import permit, drug license, submitting tender documents, obtaining ownership of land, building, and motor vehicle, getting a loan

\footnotetext{
${ }^{2}$ Prediction $H P-1$ is meaningful unless we managed to substantially lower the expected size of the penalty $E(p(D) P(D))$ by informing firms of a true penalty size $P$ that would be substantially lower from what firms presumed prior to the intervention.
} 
over 1 million BDT from commercial bank or a leasing company, renewal of membership with chamber of commerce or business associations, getting utility connection to business premises, etc.) for which a TIN is legally required and the significant penalty (BDT 20,000) involved in using a fake TIN or somebody else's TIN. The letter is signed and stamped by the NBR, and we had the letter hand delivered by agents who acted upon the approval of the tax authority and identified themselves as tax authority envoys. To make the 30 day notice period credible to the recipients, the delivery date of each of the letters is clearly marked and the tax office agents obtained a confirmation signature and date of the receipt of the letter by the firms as a part of the hand delivery process. To the best of our knowledge, this is the first stick intervention to address informality vis-a-vis tax registration in Bangladesh and, for that matter, in developing countries. ${ }^{3}$

If firms perceive such visits as credible threats, thus increasing the expected size of the penalty for informality, they would respond by registering. We note as well that our stick intervention is orthogonal to recent reforms of the tax authority that have made the registration process easy and costless. NBR eliminated the registration fee associated with obtaining a TIN (previously BDT 1000) in 2012 and launched the online registration process - eTIN - in 2013, which has eliminated any potential transaction and opportunity costs associated with a business owner's physical visit and interaction with the local tax officials. The business owner can now readily and easily obtain the TIN certificate for free through the online registration system at any time without needing to travel to their local tax office. As such, the effect of these carrots in terms of reducing the direct costs of obtaining a TIN affect both our treatment and control group in the same way.

\section{Research Design}

We implement our intervention at the market level in Dhaka, the capital city of Bangladesh, which has the country's largest concentration of economic activities and businesses. Our sample comes from a nationally representative business listing of about 56,000 firms in 19 major districts of Bangladesh conducted in 2010 and a nationally representative survey of informal firms conducted in 2011 by the World Bank Group. Based on these two sources, we constructed

\footnotetext{
${ }^{3}$ A recent paper by Khan, Khwaja, and Olken (2014) provides monetary incentives, in the form of performance pay, to tax collectors in Pakistan and finds substantial improvements in tax revenues.
} 
a sample frame of 5,000 informal firms in Dhaka clustered in about 100 small market places for our intervention. From this sample frame, we ran a baseline survey for a random sample of 3,200 informal firms in October-November 2012. The baseline survey verified that the firms were not registered with the tax authority and collected detailed information about the business and owners' characteristics. Prior to the implementation of our intervention in June 2014, we conducted a follow-up phone check to verify that the location, ownership, and informality status of the firms from the baseline survey were still intact. We were able to complete and have information on about $50 \%$ of the phone calls made, and out of those completed calls we had 253 firms declaring to have a valid TIN and another 147 had closed down for good. We dropped those 400 firms from our working sample as well as another 100 firms determined to be ineligible for the sample and should note that this step happened before the treatment or randomization was implemented. Through this process we obtained a resulting sample of 2,700 firms. Those firms were then randomly assigned to 3 possible groups: i. treatment, ii. control in treatment markets, and iii. control in control markets as detailed below. This two-step randomization (as in Angelucci and De Giorgi (2009)) was performed in order to be able to capture withinmarket spillover effects. Note that in our sampling design we attempted to produce a census of firms operating in a small market. It would seem possible that control firms may react to the visits to treatment firms, if for example by noticing the NBR official (although there is nothing conspicuous about our envoys) or by information sharing with treated firms. In order to define a specific market we first used local knowledge and administrative boundaries to subdivide the city of Dhaka into a total of 43 larger markets each with about 55 firms on average. As this procedure resulted in fairly large markets occupying a wide area, we then split the largest 29 markets into 2 or 3 submarkets minimizing the distance between firms within a submarket (cluster) so that we obtained markets with an average size of about 25 firms, irrespective of the sector. The overall procedure ultimately resulted in the definition of 93 markets, which allows us to detect possible spillovers as well as maintaining enough power to detect the main effects. Ultimately the algorithm used splits markets according to the existence of physical barriers with administrative location such as water-flows, major roads, and buildings (see Figure A.1 in the Appendix).

The resulting 93 markets were then randomly assigned to treatment or control status and firms within treatment markets were split between treatment and control firms conditionally on 
the market size in terms of number of firms in the market (terciles), sector (trade, manufacturing and services), profits (quartiles), revenues (quartiles), number of full-time employees (terciles), and number of part-time employees (halves). It is important to note that we control for these stratification variables throughout the analysis. This exercise resulted in the firms being split into 3 sets: i) treatment firms, ii) control firms in treatment markets, iii) control firms in control markets (pure controls). We ultimately obtained 1,099 pure control firms, 817 treatment firms, and the remaining 784 firms as control firms in treatment markets at the time of the intervention. A letter-delivery attempt was made to all 817 treatment firms, and of these intent-to-treat firms only 583 successful deliveries were made, representing an attrition rate of $28 \%$. The remaining firms were closed on the days of delivery. Then 234 new firms, each located in the same market as an attrited firm, were added to the sample as replacement treatment firms for inclusion in the subsequent follow-up survey. We therefore note that out of the original 817 firms randomized into the treatment sample, 583 firms were successfully treated and the 234 firms that dropped out at the intervention stage were replaced by 234 new firms located in the same market. Further, there were 371 control firms (including both pure controls and controls in treatment markets) that dropped out of the sample between the randomization and the follow-up survey and another 42 of the 583 originally-randomized treatment firms that dropped out between the intervention and the follow-up.

Overall the attrition rate for the 2,700 firms identified to be potentially in operation and not registered with the NBR is quite high at nearly $25 \%$. Specifically, we note that of the 2,700 firms determined eligible at the randomization/implementation step, 2,053 of these firms were successfully tracked from the baseline survey to the follow-up survey, with 541 being treatment firms, 643 as control firms in treatment markets, and 869 pure controls. It is worth mentioning that we also surveyed an extra 463 firms in the follow-up survey. Of these replacement firms, 234 were treated as mentioned above, 159 were assigned as pure controls, and the remaining 70 firms as controls in treatment markets. We focus our analysis on the original firms for two reasons: i. for those firms we have baseline business outcomes while we do not have the same baseline information for the replacement firms; and ii. if we include the replacement firms the results are very similar to the ones presented in the paper (see Appendix Table A.1).

In addition to this exercise, in early 2015 we attempted recontacting the 647 firms that were present in the intial randomization sample. We were successful in tracking down and surveying 
a total of 76 of these firms, of which 39 were treated firms, 16 were control firms in treatment markets, and the remaining 21 were pure controls. As the results from adding these extra 76 firms are identical to the main estimates in the text we abstract from them.

\section{Data}

We collected baseline data from October 1st to November 22nd, 2012. We then selected only those firms that declared not to be registered with the tax authority. It is important to reiterate that we tried to construct a census of firms within a given market; as explained earlier we used local knowledge as well as physical boundaries and an algorithm to define our notion of market. We collected a wealth of information on firm characteristics and business outcomes, i.e. the firm's location (including GPS coordinates), the number of full time and part-time employees, amount invested in the last quarter, monthly sales and profits, the share of sales on credit, loans amount, sources (bank, micro-credit, money lenders, family and friends) and associated interest rates, length of contractual relationships with clients, share of sales to domestic market, interaction (if any) with different government agencies (including the NBR). We also collected information on the business owner's durable consumption in the form of housing situation (owning versus renting), and value (either housing value or rent). We then collected the same information in our follow-up interviews, importantly we added a question to determine whether the business was visited by an NBR representative. Firms were re-interviewed in the follow up between September 7th and October 2nd, 2014.

As can be noted from Table 1 our sample of firms is mainly constituted by micro to small businesses ( 2 employees on average) in the trade sector (about 60 percent), while we have an almost even split of the remaining firms in the manufacturing and service sectors. Firm profits in the average month are about 15,000 Taka (BDT) (or 200USD) with average monthly revenues of about BDT 150,000. ${ }^{4}$ The implied ratio of profits over revenues is about 10 percent and seems lower than for similar populations across several countries as summarized in McKenzie and Woodruff (2012). For example, in the US the average profit margins for the 20 most profitable firms ranges between $16.5 \%$ and $10.4 \% .^{5}$

\footnotetext{
${ }^{4}$ For the relevant period the exchange rate is about 75 Taka (BDT) per USD.

${ }^{5}$ Forbes (2011), “...The data are drawn from financial statements on nearly 300,000 companies, most with under USD10 million in annual revenue, and bucketed by five- and six-digit North American Industry Classification System codes. The figures were gathered between Jan 1, 2003 and Jan 1, 2011, to capture an entire business cy-
} 


\section{TABLE 1 ****}

Importantly, although our sample at baseline is constituted exclusively by firms that are not registered with the tax authority (NBR), they do for the large part posses a trade license $(80 \%)$.

An important feature of the firms sampled is that they are essentially never visited by the tax authority, only about $1 \%$ of the firms declare to have been visited by an NBR official at baseline, which is exactly what our intervention is meant to impact upon. At the same time, our firms appear to receive visits and interact somewhat more with the city offices (about 20\%).

About $50 \%$ of the firms would like to grow and very few firms (below $5 \%$ ) seem to maintain long-term contracts. These are, together with the ability to obtain formal credit from standard banking institutions, the dimensions we believe a full formalization and registration with the NBR could impact positively. In terms of credit, most firms (about $70 \%$ in the quarter prior the interview) seem able to obtain loans, although only fewer than $5 \%$ obtain such a loan from a standard bank. Most of the credit comes from suppliers (above 80\%). So to have extra, possibly more reliable, measures of wealth we asked about home ownership ( $86 \%$ are renters), living in housing averagely valued at about $85,000 \mathrm{USD}$, while renters declare a monthly rent of about 80USD.

As can be seen from the tests provided in columns (4)-(6) our randomization was, not surprisingly, successful. Those columns show that our samples of treatment and control firms are balanced in the vast majority of the baseline observables, and importantly in those observables that we did not use as stratification variables. Of the 90 tests presented only in 8 cases may we reject the null of equality of means at the $10 \%$ level, below what one would expect from pure chance.

\section{Analysis on Tax Registration}

The empirical analysis is rather straightforward as we will be estimating the effects of a randomized controlled trial. We run a series of linear models for the outcomes of interest while clustering the standard errors at the market level. ${ }^{6}$ Further, when estimating direct treat-

\footnotetext{
cle..."See http : //www.forbes.com/sites/brettnelson/2011/02/10/the-most-profitable-small-businesses/

${ }^{6}$ We note that the results are robust to running probit models rather than linear models for the dichotomous variables.
} 
ment effects $\left(A T E^{\prime} s\right)$ we use only between market variation, i.e. comparing treatment firms in treatment markets to control firms in control markets. As long as there aren't across markets spillovers we will then be able to identify the causal effect of the treatment.

We define four outcome variables which describe whether a firm registered with the tax authority: i. self-reported registration, ii. self-reported registration plus TIN (Tax Identification Number); iii. self-reported registration plus TIN plus TIN card verification by our enumerator; iv. we combine definitions i. to iii. in an ordered variable taking four distinct values in ascending order of verifiability in the registration as such increasing our trust in the actual registration. So defined definition iv. of the dependent variable assumes the following values: $3=$ if the enumerator actually sees the TIN card, $2=$ if the interviewee self reports a TIN number, $1=$ if the interviewee self-reports being registered, $0=$ if none of the above. ${ }^{7}$

Given that the baseline value of the dependent variables is equal to zero for all firms, either a cross-sectional or difference-in-difference approach will produce very similar results in terms of both estimates and significance, we report the cross-sectional approach throughout the paper. ${ }^{8}$

\subsection{Direct Effects on Registration $\left(A T E^{\prime} s\right)$}

We start by showing in the left-most column (1) of Table 2 that indeed firms in the treatment group were visited by an NBR agent. This simply confirms that our intervention did indeed take place and suggests that the difference in the probability of being visited by an NBR representative is of about 85 percentage points with a control group mean of about 10 percentage points (some firms could be visited by other NBR officials although it is highly unlikely given the rate of visits at baseline and/or this is the measurement error one would expect in survey data). We present the main effects of the treatment on registration, moving from column 2 to 5 from the least to the most conservative (trusted) definition. We also present the mean of the corresponding dependent variable in the post intervention wave for the control group for ease of interpretation of the coefficients. In addition to that we control for the stratification variables throughout (McKenzie (2012)) to assure valid inference, and as mentioned previously, we cluster the standard errors at the market level.

**** TABLE 2 HERE****

\footnotetext{
${ }^{7}$ The TIN numbers provided by the respondents appear to be correct in all cases. We independently verified the TIN numbers using electronic payment system for taxes and found those self-reported numbers to be correct.

${ }^{8}$ The results using the diff-in-diff approach are, as it should be in this case, virtually identical.
} 
Overall, we find that the intervention is effective at increasing the rate of registration among treated firms. The effects are small in levels but extremely large in percent terms, relative to the control group. Up to three months from the intervention only up to 17 percent of the firms declare to be registered in the treatment group versus 13 percent in the control group (post intervention) (column (2)), an even smaller share can give us their registration number, 3.5 percent versus 1.1 percent (column (3)), and even fewer firms are able to show us a valid tax ID card 3.1 percent versus 0.9 percent in the control group (ex-post) (column (4)). We have a similar result if we look at our intensity measure (column (5)) although the interpretation of the coefficient is not very meaningful. We find it reassuring that the more stringent definition of registration is the outcome where we see the larger and more significant effects. However, there is a clear issue which comes to mind looking at the above results: despite the positive effect of the treatment and the threat of penalty associated with it, the vast majority of firms decide not to register with the tax authority. Even if we were to use the softest definition for registration (self-reported registration as in column (2)) we find that only below 17 percent of the treatment firms are registered by the time of our follow-up survey, and there are therefore still 83 percent of the firms that remain informal. There could be several reasons why this might be the case with the obvious explanations being: our treatment and associated threat wasn't credible enough or just negligible, or even that firms simply find it optimal not to register even if they think of the threat as credible. We tested for the following: i. too short a span between the treatment and the follow-up survey (we tested for this in unreported regressions and found no noticeable increase over the available time since the treatment. The treatment ranged from 47 to 84 days before the follow-up survey with a median time since treatment of 59 days.); ii. whether the size of the expected penalty is actually too small to be a factor in the firms' decisions (we looked for heterogeneous responses in terms of the size of the penalty over the baseline revenues (or profits) and we did not find evidence for this and in fact we will see later how this is not the determinant of registration.

\subsection{Heterogeneous Direct Effects: Baseline Revenues}

As noted in the narrative of registration (Section 2) and on the testable hypothesis $(H P-2)$, we expect firms with larger baseline revenues to be the ones responding to the treatment. The reasoning is as follows: if revenues are correlated in the non-registration and registration 
scenarios, we expect higher revenues firms to register. Clearly, we assume that even factoring in the expected tax burden, more profitable firms still optimally decide to register. This would not be the case if taxes were quite progressive. Similarly one can point out that for unprofitable firms the decision to register would not comply any direct costs, as their taxes would be zero or negligible, however once registered, firms are clearly more easily detected not complying with a series of duties including tax declaration and potentially violating labor restrictions. Further to that we expect low-revenue firms to at least believe to be able to make larger revenues in the future.

Such analysis is performed for revenues in Table 3, the table has a similar structure to the one described earlier for Table 2. The results are consistent with our hypothesis. Viewing the two strictest measures of registration (columns (3)-(4)), we see that the positive and significant effects on tax registration are concentrated among the higher revenue firms at baseline. Those effects for firms with above-median baseline revenues are now non-negligible, in levels we detect a 4.5 percentage to 5.3 percentage points effect depending on the outcome variable we look at, and obviously those effects are very large in relative terms when compared to the control group. Importantly, the effects for the below-median firms are all very close to zero and insignificant, while we can reject that the effect for firms above-median baseline revenues are the same at the $5 \%$ significance level in both cases. At the same time we present in the table a test on whether the treatment effects are in fact positive for the firms above median revenues in comparison to the above median revenues firms in the control group and in fact they are positive and significant for all the outcomes of interest but the self-reported registration status (which is the one we trust the least).

\section{**** TABLE 3 HERE****}

These findings are consistent with the view that the informal sector is heterogeneous and formalization is not for everybody. While a large number of firms operate in the informal sector, not all of these firms are necessarily highly aspirational entrepreneurs who remain in the informal sector because of the regulatory maze as posed by de Soto (1989). Rather they are subsistence-entrepreneurs who operate in the informal sector for survival in the absence of job opportunities in the formal sector as the dualistic paradigm suggests (Harris and Todaro, 1970). For instance, de Mel, McKenzie, and Woodruff (2010) find that between one-quarter 
and one-third of the self-employed appear to share characteristics that give them the potential to be owners of somewhat larger firms, while the remaining two-thirds to three-quarters look much more like wage earners. Quasi-experimental evidence from Mexico (Bruhn (2013)) and Brazil (Fajnzylber, Maloney, and Montes-Rojas (2011)) suggest that only the high-potential informal business owners who have characteristics similar to the owners of formal businesses are likely to formalize after the simplification of business entry and tax regime, albeit the effect is small particularly in the case of Mexico. Our finding on the heterogeneous effect on tax registration based on firm revenues thus complements the existing literature on formalization and suggests that rather than wasting resources and efforts to encourage formalization of the entire informal sector, policymakers would be much better off by targeting the high-potential informal firms for formalization from the perspective of increasing the revenue source. Also these high potential firms are the ones that could potentially reap the benefits of formalization most in terms of increased market and credit access; as such a well-targeted effort could be a win-win situation both for the policymakers and for the high-potential informal firms.

\subsection{Heterogeneous Direct Effects: Intensity of Treatment at the Market Level}

Treating a varying number of firms in the different markets is interesting to analyse in order to determine whether the treatment effects are a function of the intensity of the treatment at the market level. We do so following the usual tabular structure seen before and present these results in Table 4. The results suggest that the number of treated firms in a market does not affect the direct treatment effects as the point estimates are quite similar (and statistically indistinguishable) for the above- versus below-median number of treated firms in a market. As will be shown later, this result is encouraging since we are also able to perform the same test for the spillover or indirect treatment effects $\left(I T E^{\prime} s\right)$ which will allow us to assess the saliency and perception of the threat of punishment for control firms when neighboring firms receive a visit from the NBR.

**** TABLE 4 HERE**** 


\subsection{Spillover or Indirect Treatment Effects $\left(I T E^{\prime} s\right)$}

As firms in Bangladesh tend to cluster and often locate in the same building or shopping/production complex, we hypothesize that control firms in treatment markets may react to the treatment either because: i. they can see the NBR agent entering the building and delivering a letter to the treatment firms; or ii. simply via information diffusion from treated firms to control firms. In particular we expect the effect to be larger in those markets where a substantial amount of firms are treated simply because firms may be more concentrated in a given market.

As mentioned in the research design, we purposely built in the ability to test for these types of spillover effects within a given market, and in the analysis presented in this section we compare control firms in treatment markets to control firms in control markets in order to estimate the indirect treatment effects $\left(I T E^{\prime} s\right.$ ) (Angelucci and De Giorgi, 2009). We will follow the same analysis structure as for the main direct treatment effects: i. the average effects, ii. heterogeneous effects in terms of revenues as well as the number of treated firms at the market level.

\subsubsection{Average Indirect Treatment Effects}

We present the average indirect treatment effects in Table 5 preserving the same structure as the one described earlier in reference to Table 2. It is important to note that control firms in treatment markets do not receive the visit of our agents delivering the letter (column (1)). The results indicate no significant spillover effects on average for our loosest definition of registration, self-declaration (column (2)), as well as any other measure of our more stringent registration measures (columns (2)-(5)). In all cases the point estimates are close to zero and statistically insignificant. Note we control for the stratification variables and cluster the standard errors as before in the results presented.

**** TABLE 5 HERE****

\subsubsection{Indirect Treatment Effects by Baseline Revenues}

In order to investigate whether higher revenue firms not receiving treatment react to neighboring firms receiving a visit from an NBR agent we present the results shown in Table 6 below. We calculate the median level of firm revenues at baseline and then assign the non-treated firms 
to the above- or below-median groups. The table follows a similar structure as those presented earlier and we again cluster the standard errors at the market level.

**** TABLE 6 HERE****

Recall the results reported earlier for the heterogenous direct effects by baseline revenues (Table 3) in which we verified the testable hypothesis $(H P-2)$ and showed that, for the two strictest measures of registration, positive and significant effects on tax registration are concentrated amongst the higher revenue firms. The same is not true for the indirect treatment effects above and it is important to note that in none of the cases can we reject the null hypothesis that the above- and below-median coefficients are the same. Further the point estimates for both the higher revenue firms and the lower revenue firms are near zero and insignificant. Therefore we must conclude that control firms in treatment markets do not react to neighboring firms being visited by an NBR official despite whether they earn revenues above the baseline median or not.

\subsubsection{Indirect Treatment Effects by Intensity of Treatment}

It is plausible to expect the spillover effects to increase as the number of treated firms in a given market increases. As a byproduct of our research design we have that on average just over 10 firms are visited in treatment markets with a standard error of 7.57. The saliency and perception of the threat of punishment for non-treated firms in treatment markets should increase as the number of NBR visits to neighboring firms increases. We therefore test below in Table 7 whether control firms in treatment markets, while they never themselves received a visit, react positively when a "large" number of neighboring firms are visited and define this as the intensity of treatment. We assign firms in the sample to groups based on being above or below the median number of treated firms in a market. By construction, all control markets have zero treated firms and thus the pure control firms are assigned to the below-median group.

**** TABLE 7 HERE****

As clearly seen in the table we cannot detect any significant differences in the spillover effects between control firms in markets with above-median number of treated firms compared to control firms in markets with below-median number of treated firms. Further, all of the 
point estimates are statistically insignificant and near zero. These results lend credence to the validity of the randomization and implementation of the treatment, and point to the conclusion that despite neighboring firms being visited by an NBR agent, the owners of the control firms do not adjust their behavior accordingly and register with the tax authority. Thus the perceived threat of punishment does not increase as a function of the intensity of treatment at the market level.

\section{Conclusions}

It is well known that few firms tend to register for tax purposes in developing countries, and in fact informality is pervasive in Bangladesh with about $75 \%$ of the firms being not registered. This generates a low tax base, which is essential for the provision of public goods, as well as unfair competition between firms with different costs structures. At the same time the ability to remain informal and pay no taxes could preclude firms' growth as larger firms have a more difficult time remaining fully unregistered with the tax authority and obtaining a loan is easier once registered. We therefore built an experiment with the aim of increasing the registration rate for tax purposes and understand whether a tougher (threatened) enforcement could result in higher registration rates. To our knowledge this is the first experiment in a developing country setting that tries to provide credible threats in order to have firms register with the national tax authority. Ultimately we find that in absolute level terms our intervention moves few firms to register, however in relative terms we see a very large effect as we move about an extra 2.2 percent of firms to registration over a basis of just 0.9 percent. These are the average effects using our most conservative definition of registration after a maximum of 84 days since the intervention. Interestingly, and consistent with the narrative presented in Section 2, we find that only larger revenues firms register, and the treatment effects for those firms are non-negligible. ${ }^{9}$ This in turn has an important policy implication. Given the heterogeneity of the informal sector: rather than attempting to formalize the entire informal sector, policymakers could be much better off if they could successfully target the high-end informal firms for formalization. This, on the one hand, would be a more efficient use of public resources to generate public revenue through formalization, and on the other hand, these may

\footnotetext{
${ }^{9}$ We note that this result is also consistent with what was found in Calderon, Cunha, and De Giorgi (2014) in the context of business literacy training for similarly sized firms.
} 
be the firms who could benefit most through formalization in terms of access to market and credit.

Given the small absolute effects that we find from this experiment, the main question of whether formalization causes better business outcomes cannot be addressed. Further, we are left with a very large fraction of the firms yet unregistered even though threatened to be fined. Unfortunately, we cannot say whether this results from a lack of threat credibility or simply because small firms would not be profitable if they were to register. Given the low-cost of the intervention we conducted (overall delivering the letter costed about $225 \mathrm{BDT}$ ) the treatment would pass a cost and benefits analysis and from this perspective, we therefore recommend lowincome countries adopt a similar stick treatment. However, in order to make such interventions more successful we believe one needs to engineer more credible threats. 


\section{References}

Angelucci, M., and G. De Giorgi (2009): "Indirect Effects of an Aid Program: How to Cash Transfers Affect Ineligibles' Consumption?," American Economic Review, 99(1), 486508 .

Bruhn, M. (2013): "A tale of two species: Revisiting the effect of registration reform on informal business owners in Mexico," Journal of Development Economics, 103, 275-283.

Calderon, G., J. Cunha, and G. De Giorgi (2014): "Business Literacy and Development: Evidence from a Randomized Conrolled Trial in Rural Mexico," mimeo.

De Andrade, G., M. Bruhn, and D. McKenzie (2013): "A helping hand or the long arm of the law? Experimental evidence on what governments can do to formalize firms," World Bank Policy Research Paper, (6435).

De Giorgi, G., and A. Rahman (2013): "SME's Registration: Evidence from an RCT in Bangladesh," Economics Letters, 120(3), 573-578.

De Mel, S., D. McKenzie, and C. Woodruff (2010): Who are the Microenterprise Owners? Evidence from Sri Lanka on Tokman versus De Sotopp. 63-87. University of Chicago Press.

- (2012): "The demand for, and consequences of, formalization among informal firms in Sri Lanka," Policy Research Working Paper Series 5991, The World Bank.

DE Soto, H. (1989): "The Other Path: The Invisible Revolution in the Third World," .

Fajnzylber, P., W. F. Maloney, and G. V. Montes-Rojas (2011): "Does formality improve micro-firm performance? Evidence from the Brazilian SIMPLES program," Journal of Development Economics, 94(2), 262-276.

Harris, J. R., ANd M. P. Todaro (1970): "Migration, Unemployment \& Development: A Two-Sector Analysis," American Economic Review, 60(1), 126-42.

Khan, A., A. Khwaja, and B. Olken (2014): "Tax Farming Redux: Experimental Evidence on Performance Pay for Tax Collectors," NBER-WP, (20627).

Loayza, N. V., And J. Rigolini (2006): "Informality trends and cycles," Policy Research Working Paper Series 4078, The World Bank.

McKenzie, D. (2012): "Beyond Baseline and Follow-Up: The Case for More T in Experiments," Journal of Development Economics, 99(2), 210-221.

McKenzie, D., And C. Woodruff (2012): "What are we learning from business training and entrepreneurship evaluations around the developing world?," Policy Research Working Paper Series 6202, The World Bank.

Schneider, F. (2005): "Shadow economies around the world: what do we really know?" European Journal of Political Economy, 21(3), 598-642. 
Table 1: Balance table

\begin{tabular}{|c|c|c|c|c|c|c|c|c|}
\hline Variable & & $\begin{array}{c}(1) \\
\text { Treatment } \\
\text { Firms }\end{array}$ & $\begin{array}{c}\text { (2) } \\
\text { Control Firms } \\
\text { in Control Mkts }\end{array}$ & $\begin{array}{c}\text { (3) } \\
\text { Control Firms } \\
\text { in Treatment Mkts }\end{array}$ & $\begin{array}{c}(4) \\
\text { Test (1)=(2) }\end{array}$ & $\begin{array}{c}(5) \\
\text { Test }(1)=(3)\end{array}$ & $\begin{array}{c}(6) \\
\text { Test }(2)=(3)\end{array}$ & $\begin{array}{c}\text { (N) } \\
\text { Observations }\end{array}$ \\
\hline Number of firms & & 541 & 869 & 643 & & & & \\
\hline Profits (BDT) & & $\begin{array}{l}14,918.669 \\
(1,012.278)\end{array}$ & $\begin{array}{l}13,779.373 \\
(1,038.094)\end{array}$ & $\begin{array}{c}13,616.019 \\
(721.939)\end{array}$ & 0.434 & 0.0982 & 0.897 & 2,053 \\
\hline Revenues (BDT) & & $\begin{array}{c}132,133.457 \\
(9,903.381)\end{array}$ & $\begin{array}{l}123,690.334 \\
(14,185.404)\end{array}$ & $\begin{array}{c}124,974.495 \\
(8,243.795)\end{array}$ & 0.627 & 0.435 & 0.938 & 2,053 \\
\hline Type of Enterprise = Trade & (1=yes, $0=$ otherwise) & $\begin{array}{c}0.606 \\
(0.030)\end{array}$ & $\begin{array}{c}0.601 \\
(0.038)\end{array}$ & $\begin{array}{c}0.627 \\
(0.030)\end{array}$ & 0.908 & 0.519 & 0.592 & 2,053 \\
\hline Type of Enterprise = Manufacturing & (1=yes, $0=$ otherwise) & $\begin{array}{c}0.181 \\
(0.024)\end{array}$ & $\begin{array}{c}0.199 \\
(0.021)\end{array}$ & $\begin{array}{c}0.148 \\
(0.019)\end{array}$ & 0.571 & 0.222 & 0.0723 & 2,053 \\
\hline Type of Enterprise = Service & (1=yes, $0=$ otherwise) & $\begin{array}{c}0.213 \\
(0.023)\end{array}$ & $\begin{array}{c}0.200 \\
(0.024)\end{array}$ & $\begin{array}{c}0.226 \\
(0.020)\end{array}$ & 0.714 & 0.601 & 0.422 & 2,053 \\
\hline Total number of employees & & $\begin{array}{c}2.120 \\
(0.075)\end{array}$ & $\begin{array}{c}2.067 \\
(0.099)\end{array}$ & $\begin{array}{c}2.000 \\
(0.076)\end{array}$ & 0.668 & 0.167 & 0.593 & 2,053 \\
\hline Number of full-time employees & & $\begin{array}{c}1.943 \\
(0.068)\end{array}$ & $\begin{array}{c}1.818 \\
(0.078)\end{array}$ & $\begin{array}{c}1.835 \\
(0.076)\end{array}$ & 0.231 & 0.151 & 0.876 & 2,053 \\
\hline Number of part-time employees & & $\begin{array}{c}0.177 \\
(0.030)\end{array}$ & $\begin{array}{c}(0.026) \\
0.177\end{array}$ & $\begin{array}{c}0.249 \\
(0.041)\end{array}$ & 0.165 & 0.701 & 0.0890 & 2,053 \\
\hline What is your percentage share of sales market (Domestic) & (1=yes, $0=$ otherwise) & $\begin{array}{l}99.926 \\
(0.073)\end{array}$ & $\begin{array}{l}99.965 \\
(0.033)\end{array}$ & $\begin{array}{l}100.000 \\
(0.000)\end{array}$ & 0.623 & 0.312 & 0.301 & 2,053 \\
\hline Is your business registered with a Trade License (TL) & (1=yes, $0=$ otherwise) & $\begin{array}{c}0.787 \\
(0.035)\end{array}$ & $\begin{array}{c}0.797 \\
(0.032)\end{array}$ & $\begin{array}{c}0.792 \\
(0.025)\end{array}$ & 0.839 & 0.863 & 0.900 & 2,044 \\
\hline Did you invest in your business (fixed capital) during the last three months & (1=yes, $0=$ otherwise) & $\begin{array}{c}0.146 \\
(0.020)\end{array}$ & $\begin{array}{l}0.167 \\
(0.024)\end{array}$ & $\begin{array}{c}0.129 \\
(0.018)\end{array}$ & 0.499 & 0.324 & 0.210 & 2,053 \\
\hline Did you have to interact e.g. received a visit from any of the agencies below? & (1=yes, $0=$ otherwise) & $\begin{array}{c}0.203 \\
(0.037)\end{array}$ & $\begin{array}{c}0.209 \\
(0.035)\end{array}$ & $\begin{array}{c}0.198 \\
(0.036)\end{array}$ & 0.904 & 0.785 & 0.813 & 2,053 \\
\hline City Corporation/Municipality & (1=yes, $0=$ otherwise) & $\begin{array}{c}0.196 \\
(0.036)\end{array}$ & $\begin{array}{c}0.196 \\
(0.036)\end{array}$ & $\begin{array}{c}0.188 \\
(0.037)\end{array}$ & 0.995 & 0.701 & 0.884 & 2,053 \\
\hline Local tax office & (1=yes, $0=$ otherwise) & $\begin{array}{c}0.011 \\
(0.006)\end{array}$ & $\begin{array}{c}0.008 \\
(0.004)\end{array}$ & $\begin{array}{c}0.005 \\
(0.003)\end{array}$ & 0.662 & 0.304 & 0.523 & 2,053 \\
\hline Local VAT office & (1=yes, $0=$ otherwise) & $\begin{array}{c}0.068 \\
(0.024)\end{array}$ & $\begin{array}{c}0.047 \\
(0.012)\end{array}$ & $\begin{array}{c}0.078 \\
(0.022)\end{array}$ & 0.425 & 0.552 & 0.221 & 2,053 \\
\hline Is your business smaller than the size you want it & (1=yes, $0=$ otherwise) & $\begin{array}{c}0.482 \\
(0.041)\end{array}$ & $\begin{array}{c}0.490 \\
(0.032)\end{array}$ & $\begin{array}{c}0.498 \\
(0.036)\end{array}$ & 0.882 & 0.612 & 0.878 & 2,053 \\
\hline Is your business larger than the size you want it & (1=yes, $0=$ otherwise) & $\begin{array}{c}0.070 \\
(0.019)\end{array}$ & $\begin{array}{c}0.123 \\
(0.017)\end{array}$ & $\begin{array}{c}0.098 \\
(0.024)\end{array}$ & 0.0419 & 0.0948 & 0.395 & 2,053 \\
\hline Is your business the exactly the size you want it & (1=yes, $0=$ otherwise) & $\begin{array}{c}0.818 \\
(0.039)\end{array}$ & $\begin{array}{c}0.729 \\
(0.029)\end{array}$ & $\begin{array}{c}0.780 \\
(0.043)\end{array}$ & 0.0722 & 0.320 & 0.329 & 1,046 \\
\hline In an average month how much (in \%) of your total sales is on credit & (1=yes, $0=$ otherwise) & $\begin{array}{c}8.335 \\
(0.955)\end{array}$ & $\begin{array}{c}8.284 \\
(0.909)\end{array}$ & $\begin{array}{c}8.343 \\
(0.667)\end{array}$ & 0.969 & 0.989 & 0.958 & 2,045 \\
\hline Do you have long-term relationships/contracts & (1=yes, $0=$ otherwise) & $\begin{array}{c}0.018 \\
(0.010)\end{array}$ & $\begin{array}{c}0.039 \\
(0.024)\end{array}$ & $\begin{array}{c}0.016 \\
(0.007)\end{array}$ & 0.427 & 0.658 & 0.348 & 2,053 \\
\hline Were you able to obtain a loan in the past quarter & (1=yes, $0=$ otherwise) & $\begin{array}{c}0.639 \\
(0.038)\end{array}$ & $\begin{array}{c}0.661 \\
(0.031)\end{array}$ & $\begin{array}{c}0.684 \\
(0.031)\end{array}$ & 0.648 & 0.159 & 0.612 & 1,952 \\
\hline Loan obtained was a from a bank & (1=yes, $0=$ otherwise) & $\begin{array}{c}0.028 \\
(0.007)\end{array}$ & $\begin{array}{c}0.038 \\
(0.008)\end{array}$ & $\begin{array}{c}0.033 \\
(0.008)\end{array}$ & 0.327 & 0.501 & 0.623 & 2,053 \\
\hline Loan obtained was from Micro-credit & (1=yes, $0=$ otherwise) & $\begin{array}{c}0.089 \\
(0.012)\end{array}$ & $\begin{array}{c}0.070 \\
(0.013)\end{array}$ & $\begin{array}{c}0.092 \\
(0.015)\end{array}$ & 0.306 & 0.835 & 0.278 & 2,053 \\
\hline Loan obtained was from a money lender & (1=yes, $0=$ otherwise) & $\begin{array}{c}0.006 \\
(0.004)\end{array}$ & $\begin{array}{c}0.001 \\
(0.001)\end{array}$ & $\begin{array}{c}0.006 \\
(0.003)\end{array}$ & 0.304 & 0.893 & 0.110 & 2,042 \\
\hline Loan obtained was from family or friends & (1=yes, $0=$ otherwise) & $\begin{array}{c}0.074 \\
(0.012)\end{array}$ & $\begin{array}{c}0.066 \\
(0.012)\end{array}$ & $\begin{array}{c}0.084 \\
(0.013)\end{array}$ & 0.627 & 0.533 & 0.305 & 2,053 \\
\hline Suppliers' credit as \% of total credit & & $\begin{array}{l}84.630 \\
(2.448)\end{array}$ & $\begin{array}{l}86.715 \\
(2.187)\end{array}$ & $\begin{array}{l}81.934 \\
(2.553)\end{array}$ & 0.527 & 0.221 & 0.159 & 1,192 \\
\hline Are you able to hire and fire your employees at your will & (1=yes, $0=$ otherwise) & $\begin{array}{c}0.991 \\
(0.004)\end{array}$ & $\begin{array}{c}0.986 \\
(0.008)\end{array}$ & $\begin{array}{c}0.983 \\
(0.005)\end{array}$ & 0.592 & 0.149 & 0.715 & 2,053 \\
\hline Do you rent or won your house/apartment & (1=rent, $0=o w n)$ & $\begin{array}{c}0.860 \\
(0.018)\end{array}$ & $\begin{array}{c}0.877 \\
(0.017)\end{array}$ & $\begin{array}{c}0.871 \\
(0.018)\end{array}$ & 0.491 & 0.573 & 0.811 & 2,053 \\
\hline What is the approximate market value of the house/apartment you live & (BDT) & $\begin{array}{c}6520945.946 \\
(701,168.754)\end{array}$ & $\begin{array}{c}5494626.168 \\
(644,122.581)\end{array}$ & $\begin{array}{c}5521084.337 \\
(671,225.390)\end{array}$ & 0.285 & 0.271 & 0.977 & 266 \\
\hline If rented, what is the monthly rent of your house/apartment & (BDT) & $\begin{array}{l}5,654.882 \\
(312.913) \\
\end{array}$ & $\begin{array}{l}4,852.231 \\
(263.302) \\
\end{array}$ & $\begin{array}{l}4,962.321 \\
(213.661) \\
\end{array}$ & 0.0528 & 0.00628 & 0.746 & 1787 \\
\hline
\end{tabular}

Std.err. presented in parenthesis below the mean values. Pvalue for the tests of equality of means, in column (4)-(6),

Std.err. presented in parenthesis below the mean values. Pvalue for the tests of equality of means, in
performed controlling for the stratification variables and clustering the std.err. at the market level. 


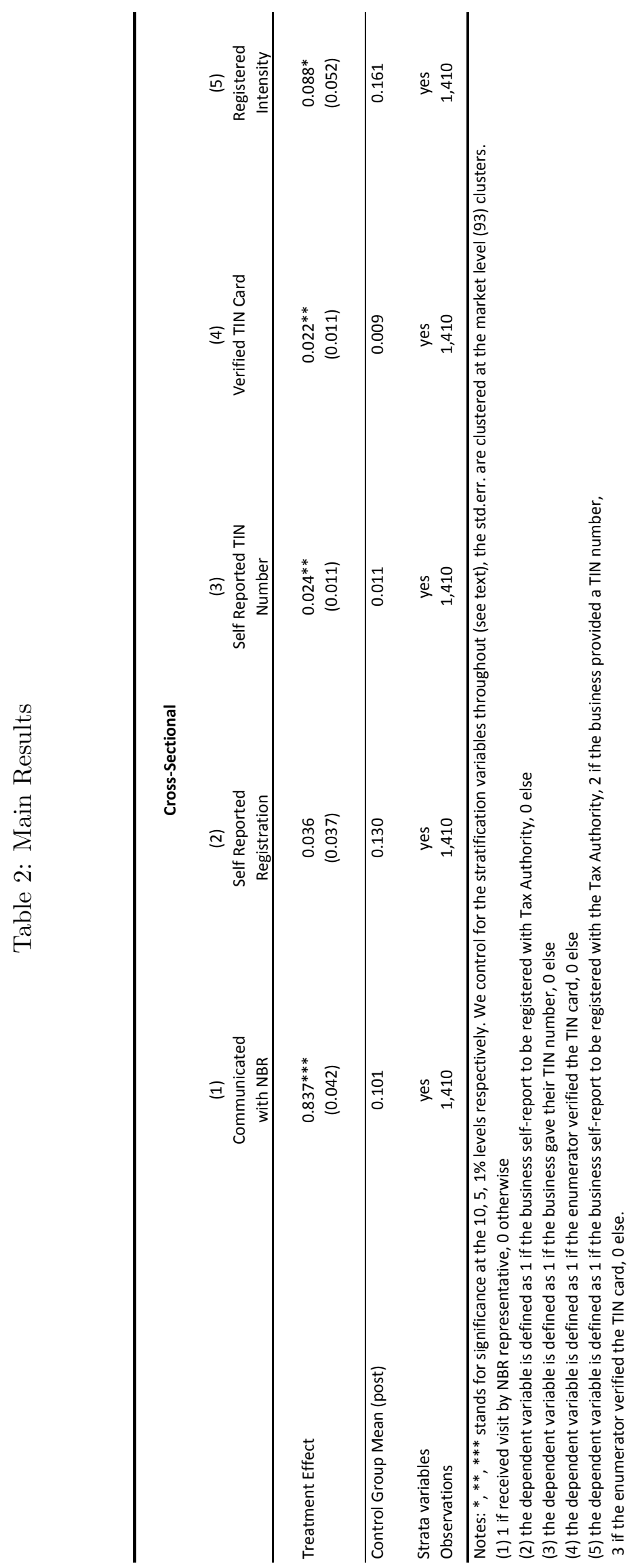




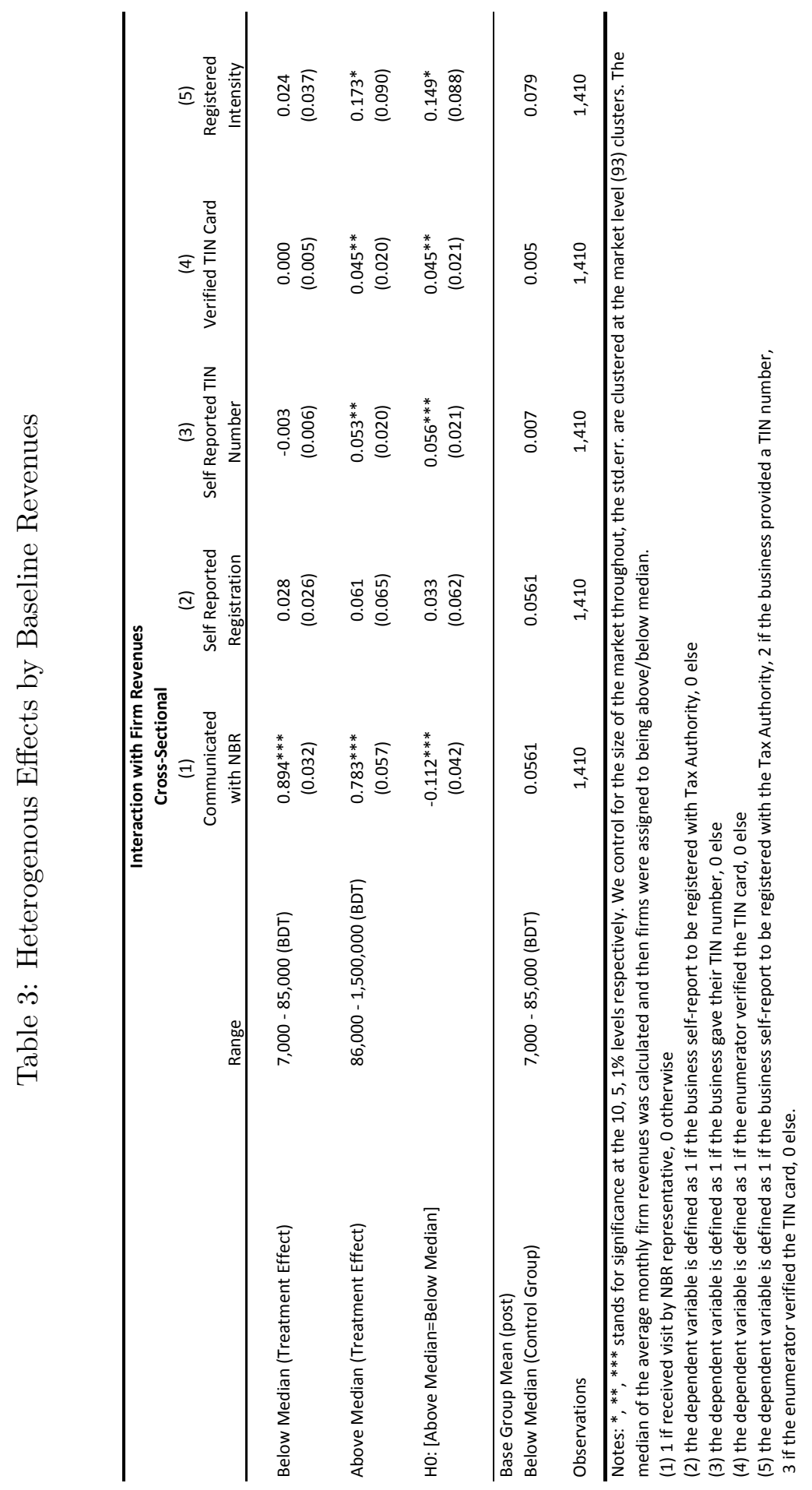




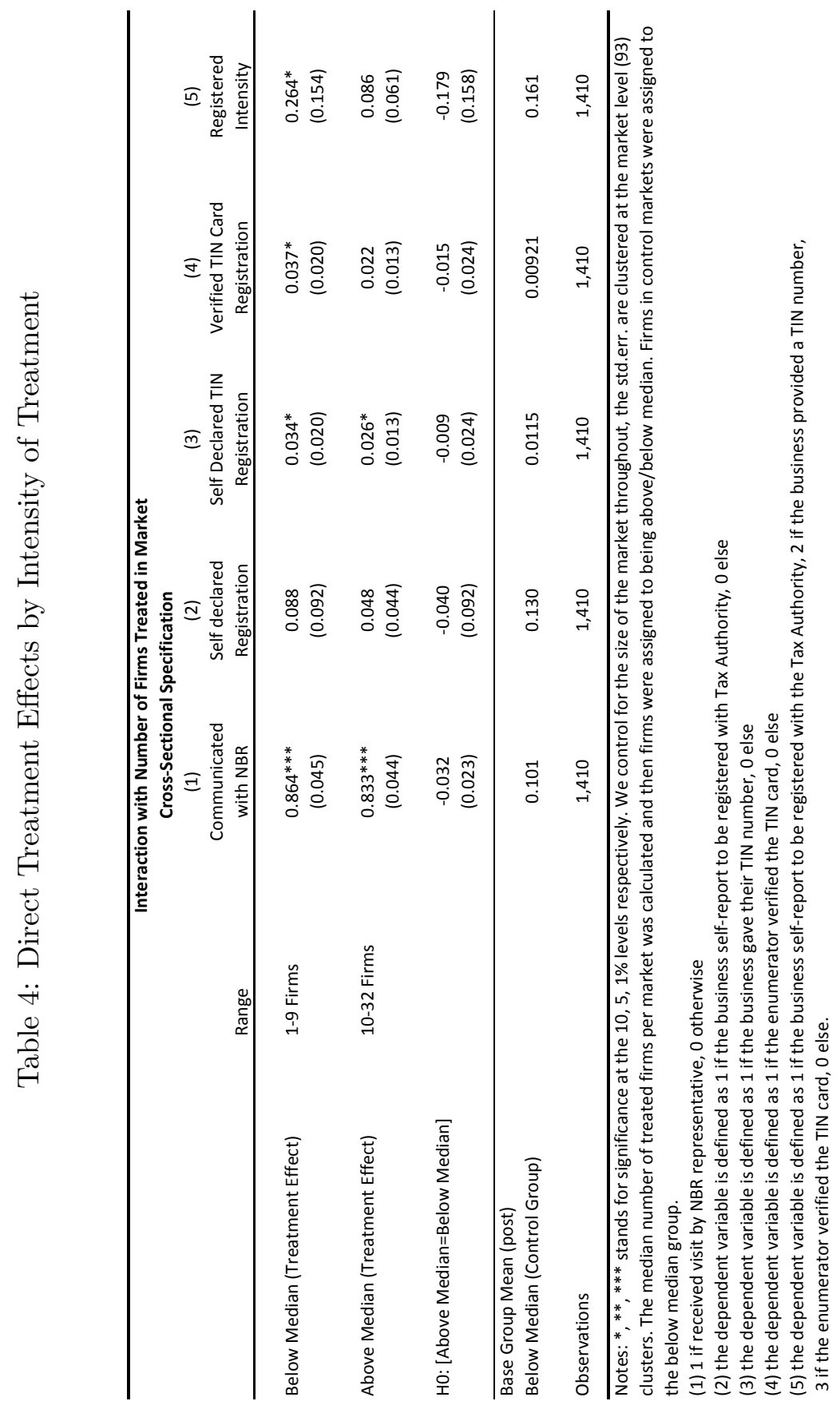




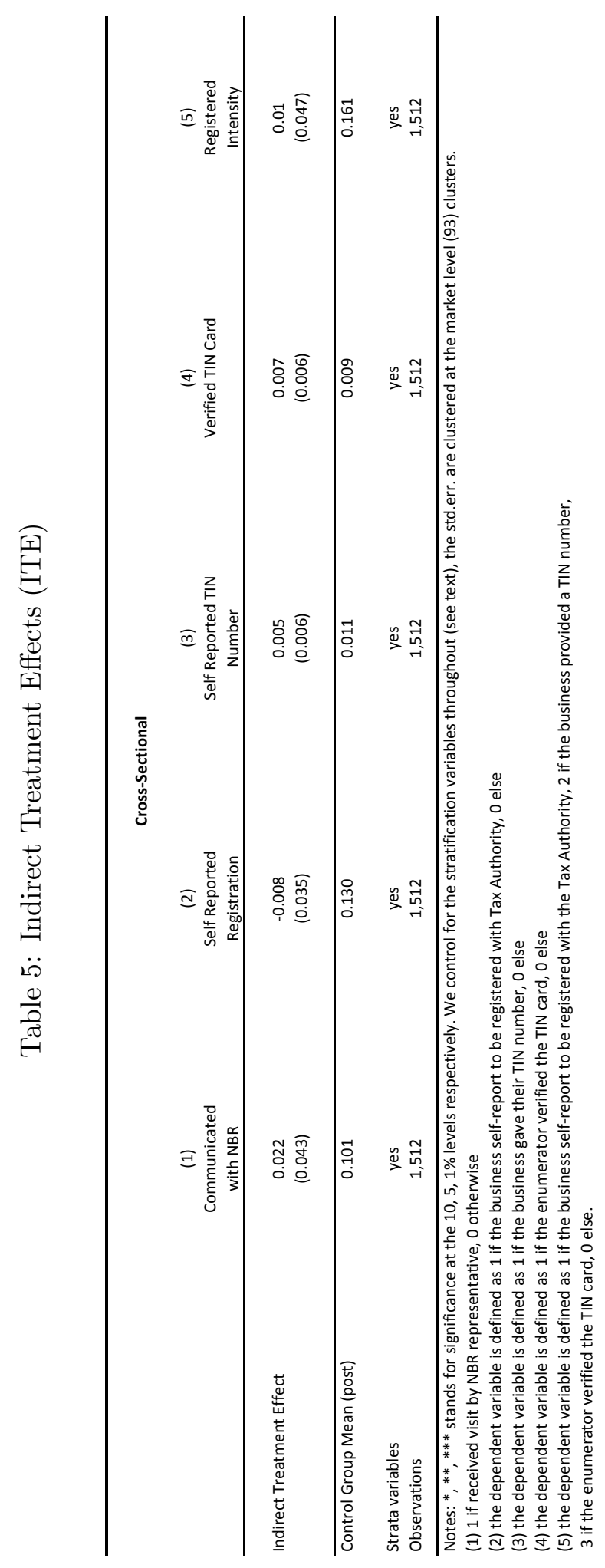




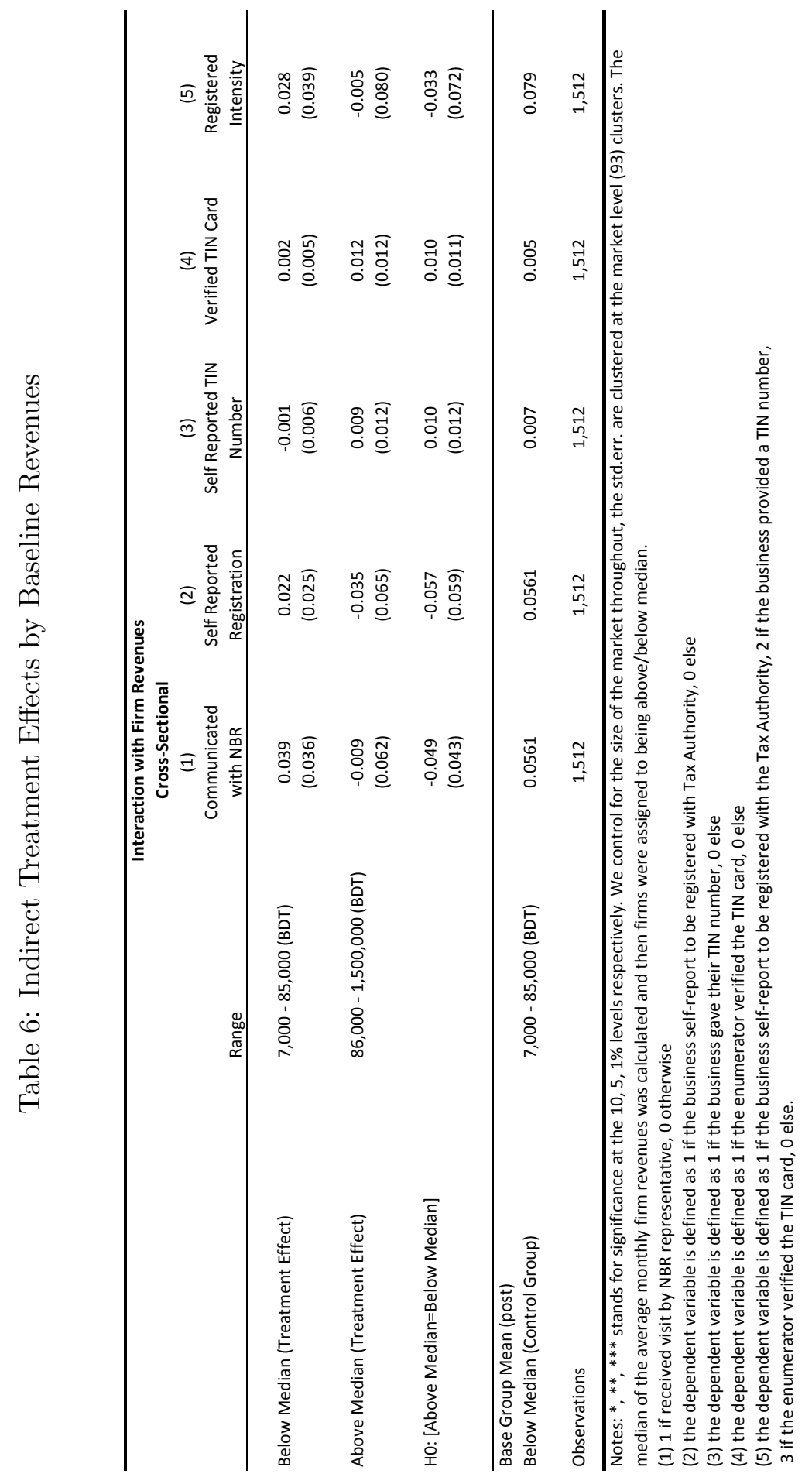




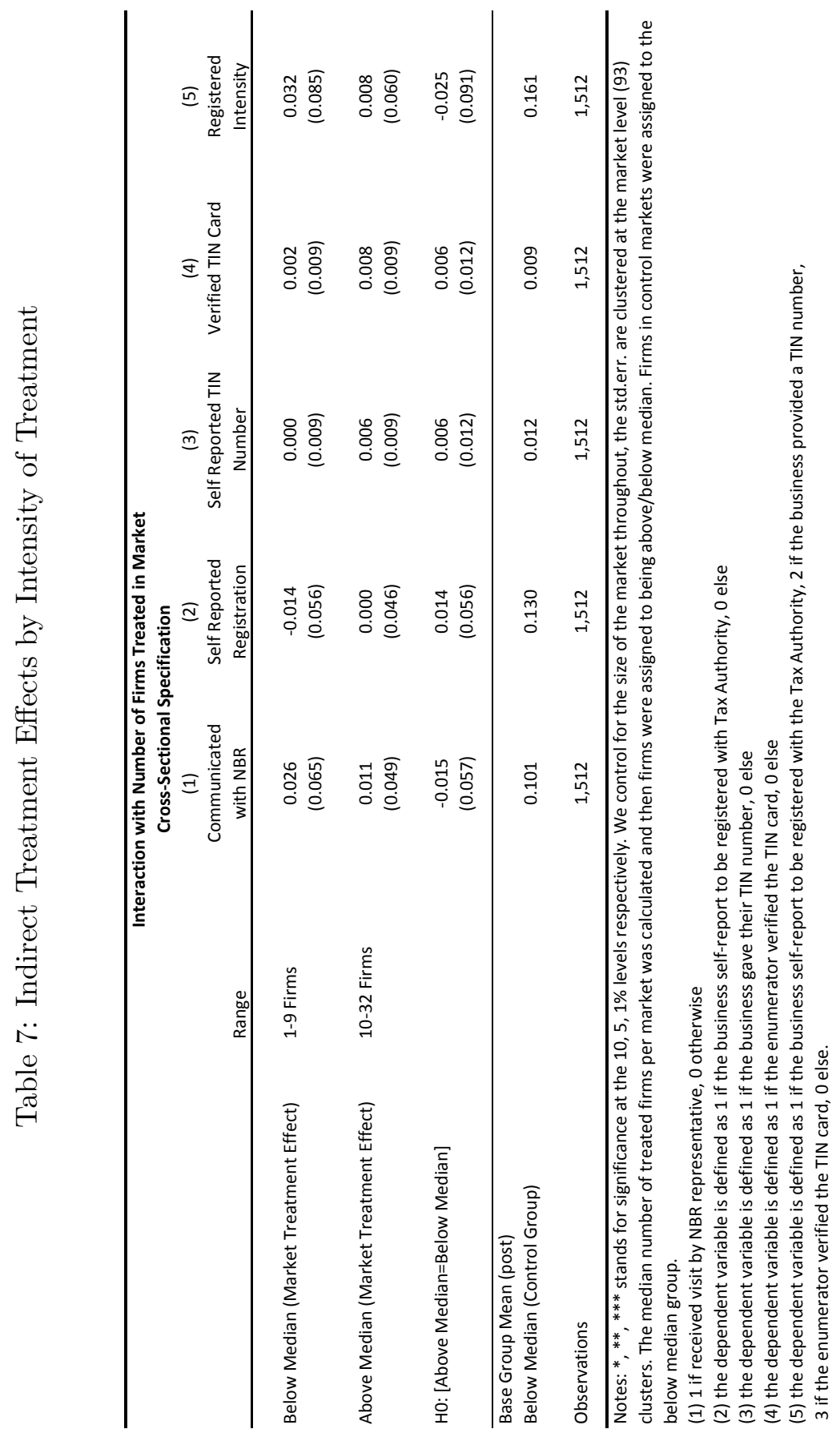




\section{A Appendix}

A.1 Letter and Map 
The Government of Bangladesh

\section{National Board of Revenue, Treasury Building}

Segun Bagicha, Dhaka-1000

Date of Delivery: 2014

NBR File Number: $X X X X X X X X X X X X X X X X X X X$

Re Obtaining the TIN Certificate

- According to NBR records, you don't

\section{have a TIN}

Name and Address of the Recipient

- You are advised to obtain the TIN certificate within next 30 days

\section{Ref: Your TIN Certificate}

The government makes it compulsory for all taxable institutions and persons to obtain the Tax Identification Number (TIN) certificate. In this regard, the National Board of Revenue (NBR) notices that currently you do not have a TIN. As per the Income Tax Ordinance 1984, you must obtain the TIN certificate. You are advised to obtain the TIN certificate within $\mathbf{3 0}$ days of receiving this letter.

You can obtain the TIN certificate easily and free of charge from www.incometax.gov.bd or from your local tax office.

- You can easily obtain TIN free of cost

from www.incometax.gov.bd website

or from your local tax office

- If you fail to show the TIN certificate during the inspection by NBR officials or representatives, you and your business will be subject to penalty of significant sum of money and other punitive legal measures as per the Income Tax Ordinance 1984.

Once the 30-day time limit is over, the NBR officials or

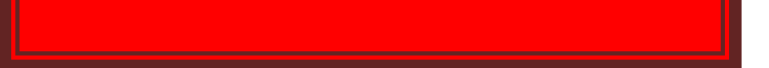
representatives will inspect if your business has a TIN or not. If you fail to show the TIN certificate during that inspection, the NBR will be obliged to impose instant fine and other punitive legal measures against you and your business as per the Income Tax Ordinance, 1984.

Please read carefully the following information:

1. Are you aware of that if you fail to display the taxpayer's identification number (TIN) certificate, you need to pay a penalty of TK. 500 and from thereon TK. 250 per month (or a fraction of the month) in case of continuing default.

2. If you use another person's TIN or a fake TIN on income tax return or in any other document or transaction where a TIN is required as per the Income Tax Ordinance 1984, then you could be subject to a penalty of TK. 20000 (twenty thousand).

You should also know that you are required to have a TIN for many important purposes including the following:

1. To open a letter of credit for import.

2. To get an import registration certificate.

3. Renewal of a trade license. 
4. Submitting tender documents for the purpose of supply of goods, execution of a contract or for rendering services.

5. To obtain membership of any club or association registered under the Company Act 1994.

6. To be enlisted as a surveyor for Sadharan Bima.

7. To purchase any land, building, or flat under the jurisdiction of the City Corporation and exceeding the registration value of TK. 100,000.

8. For vehicle registration or vehicle fitness certificate.

9. To obtain a credit card.

10. To obtain a license for doctor, chartered accountant, cost and management accountant, lawyer, or tax advisor.

11. To get an ISD telephone connection.

12. To be a shareholder of a registered company.

13. A license as a Marriage and Divorce Registrar under the Muslim Marriages and Divorces (Registration) Act.

14. Renewal of membership of a chamber of commerce and industries or any trade body.

15. Submitting a plan for construction of building for approval from the Capital Development Authority (Rajdhani Unnyan Kartipakkha, Rajuk), Chittagong Development Authority, Khulna Development Authority, and the Rajshahi Development Authority.

16. To obtain natural gas connection for commercial purposes in the areas under the jurisdiction of the City Corporation, Municipality, or Cantonment Board.

17. To transfer or renew the licenses for rentals of Trucks, Bus, Lorry.

18. To obtain and renew licenses for water transports.

19. To obtain the license of an insurance agent.

You are advised to obtain your TIN certificate either from the above stated Website or from your local tax office as soon as possible and no later than $\mathbf{3 0}$ days of receiving this letter.

\section{Sincerely,}

(Signature)

$\operatorname{XXXXXXXXX}$

Director (In charge)

Research and Statistics Division

National Board of Revenue, Dhaka

Phone: 02-9337693 


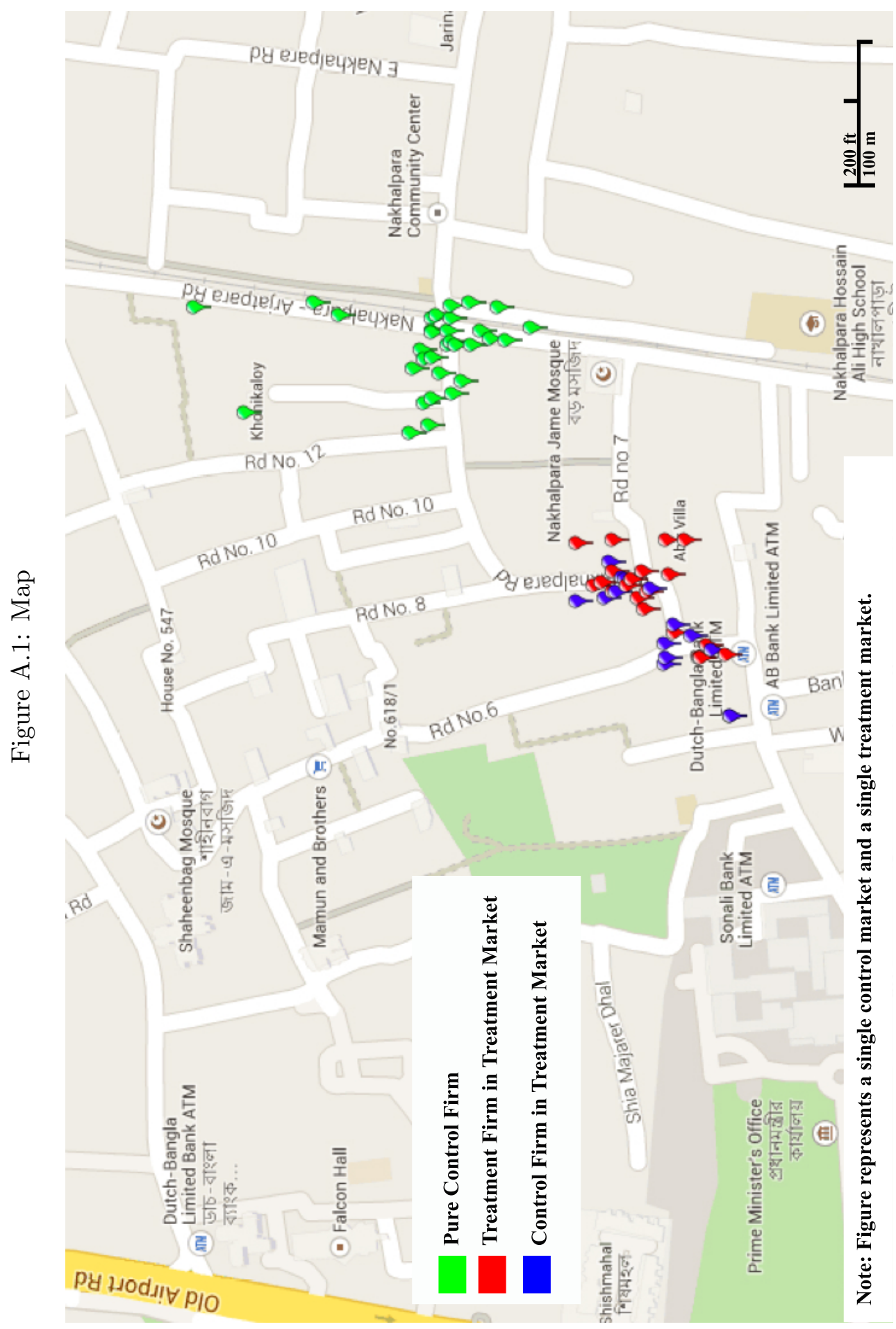




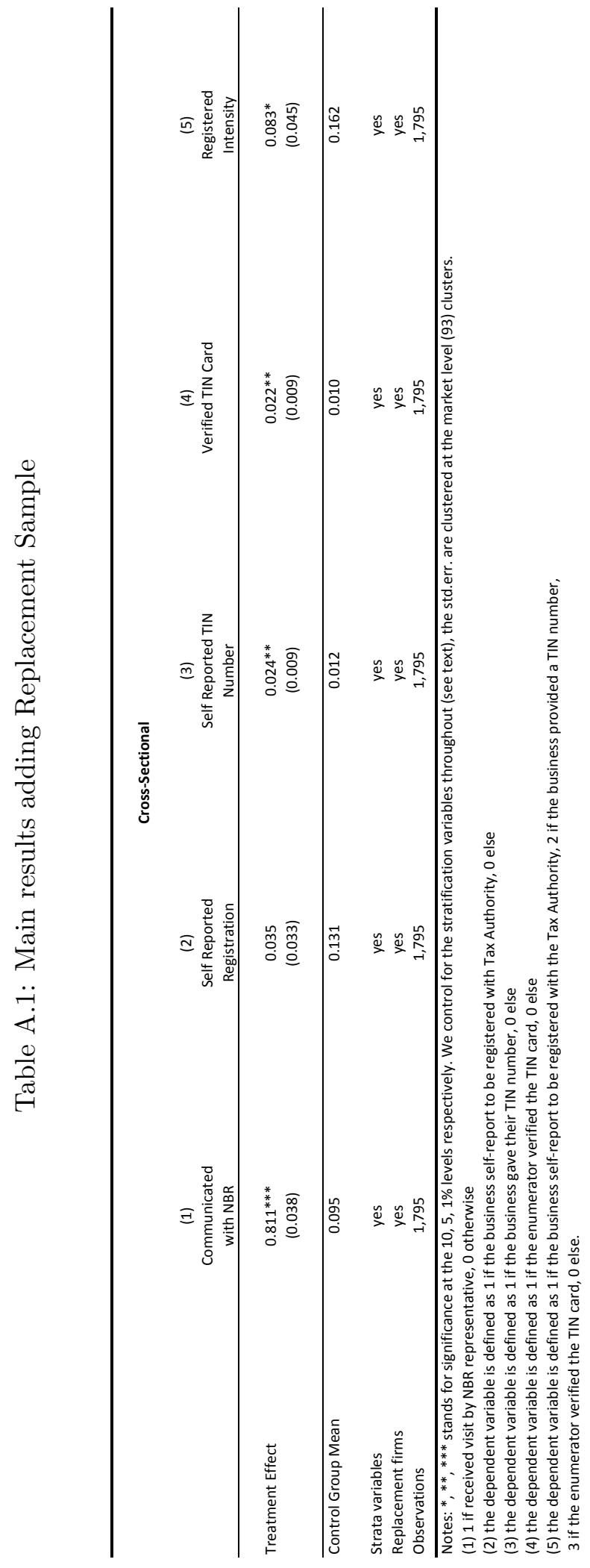




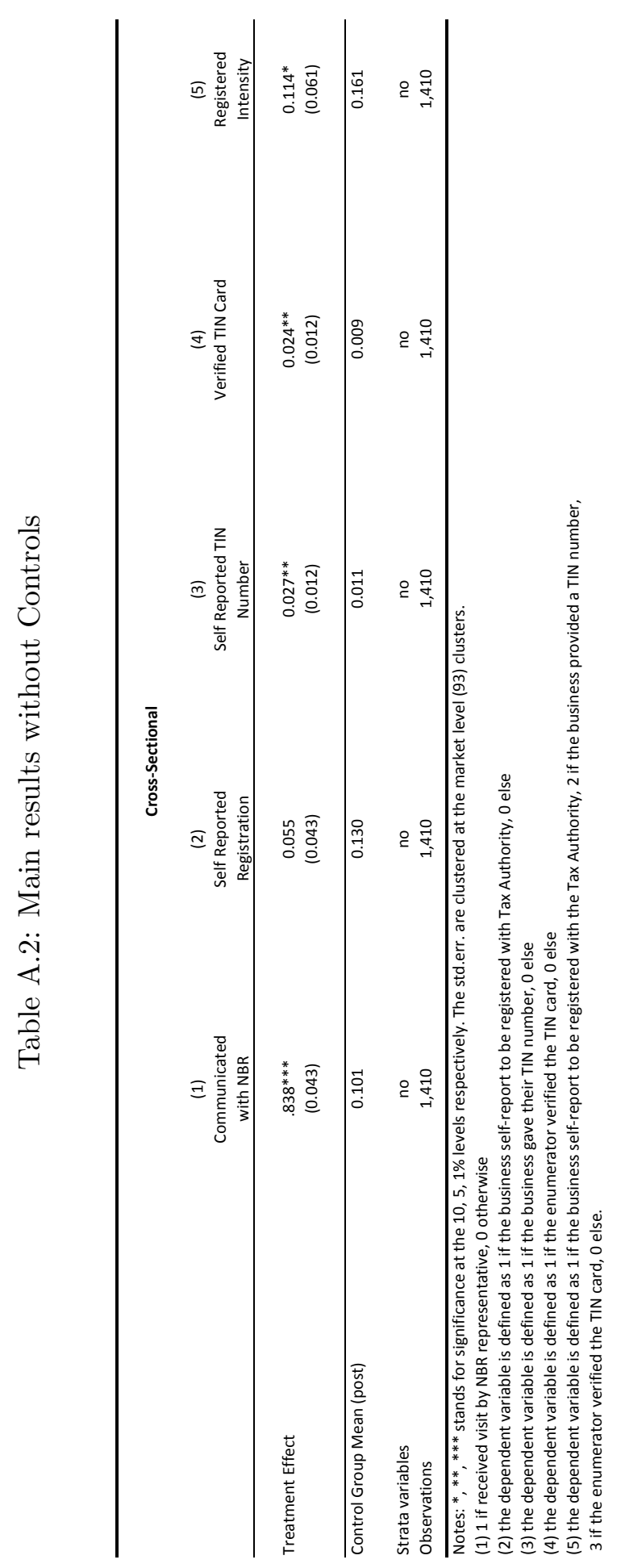

